\title{
CURSO DE FRANCÊS DO PROJETO FORMAÇÃO EM LÍNGUAS PARA FINS ACADÊMICOS: CONSIDERAÇÕES SOBRE OS MATERIAIS DIDÁTICOS E SUAS CONTRIBUIÇÕES METODOLÓGICAS
}

\author{
Curso de francés del proyecto Formación en lenguas con fines \\ Académicos: consideraciones sobre los materiales didácticos y sus \\ contribuciones metodológicas
}

Teurra FERNANDES VAILATTI Universidade Federal do Paraná (UFPR) teurravailatti@hotmail.com https://orcid.org/0000-0002-7294-4356

RESUMO: Neste estudo, analisamos materiais didáticos elaborados pelos professores em formação do Curso de Francês, ofertado durante o ano letivo de 2012, pelo projeto de extensão Formação em Línguas para Fins Acadêmicos (IFA), da Universidade Federal do Paraná (UFPR). A partir da análise qualitativa, interpretativa e documental dos programas de formação, dos materiais didáticos e de textos diretivos complementares, retomamos aspectos da estrutura das Unidades Temáticas e da exploração pedagógica dos textos autênticos. Ainda, apresentamos as contribuições metodológicas dos materiais, sobretudo em comparação com a estrutura comum aos livros didáticos de Francês Língua Estrangeira (FLE), que seguem a abordagem comunicativa. A discussão está fundamentada nos conceitos de enunciado e de gêneros discursivos da teoria bakhtiniana de linguagem (BAKHTIN, 1992, 1998; VOLÓCHINOV, 2017) e em conceitos da Didática de Ensino de Línguas (PUREN, 1988; CUQ; GRUCA, 2005; TILIO, 2013; ROJO, 2013). Formalizar um estudo a partir desse recorte promove um diálogo com outras investigações da área e contribui para a estruturação de cursos que busquem se inspirar nesta proposta ou que já se assemelhem a ela, seja na UFPR ou em outras instituições de ensino superior. PALAVRAS-CHAVE: materiais didáticos; metodologia; ensino de línguas; francês.

RESUMEN: En el estudio se analizaron materiales didácticos elaborados por los docentes del Curso de Francés, ofertado durante el año lectivo del 2012, en el proyecto Formación en lenguas con fines Académicos (IFA), de la Universidad Federal de Paraná (UFPR). Desde el

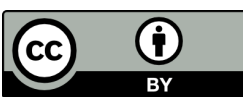


análisis cualitativo, interpretativo y documental de programas de formación, materiales didácticos y textos directivos complementarios, recuperamos los aspectos de la estructura de las Unidades Temáticas y la exploración pedagógica de textos auténticos. Además, presentamos las contribuciones metodológicas de los materiales, especialmente en comparación con la estructura común a los libros de texto de Francés como Lengua Extranjera (FLE), que siguen el Enfoque Comunicativo. La discusión se basa en los conceptos de enunciación y géneros discursivos de la teoría bakhtiniana del lenguaje (BAKHTIN, 1992, 1998; VOLÓCHINOV, 2017), y en conceptos de Didáctica de la Enseñanza de Lenguas (PUREN, 1988; CUQ; GRUCA, 2005; TILIO, 2013; ROJO, 2013). E1 hecho de realizar de un estudio desde este punto de vista promueve el diálogo con otras investigaciones del área y contribuye a la estructuración de cursos que buscan inspirarse en esta propuesta o que ya se asemejan a ella, sea en la UFPR u otras instituciones de educación superior. PALABRAS-CLAVE: materiales didácticos; metodología; enseñanza de lenguas; francés.

\section{CONSIDERAÇÕES INICIAIS: O CURSO DE FRANCÊS DO PROJETO FORMAÇÃO EM LÍNGUAS PARA FINS ACADÊMICOS E A PROPOSTA DE ANÁLISE DOS MATERIAIS DIDÁTICOS}

No ano de 2012, o projeto Idiomas para Fins Acadêmicos (IFA) ${ }^{1}$ fazia parte das ações da Pró-Reitoria de Assuntos Estudantis (PRAE), através de sua Coordenação de Assistência Estudantil e do Programa de Bolsa Permanência do MEC (PBP/MEC), na Universidade Federal do Paraná (UFPR). O projeto, registrado junto ao Departamento de Teoria e Prática de Ensino (DTPEN), do Setor de Educação da UFPR, objetivava oportunizar a formação linguística, cultural e discursiva em línguas estrangeiras ${ }^{2}$ à comunidade acadêmica cadastrada no Programa de Bolsa Permanência (PROBEM), e estruturava-se a partir de quatro módulos semestrais de 45 horas, totalizando 180 horas.

Ao tornar acessível a formação em línguas para alunas e alunos de graduação, o IFA promovia uma melhor inserção da comunidade acadêmica nos espaços do ensino superior, possibilitando, por exemplo, o acesso às atividades que exigiam o domínio das línguas ofertadas, além de contribuir, de modo mais amplo, para o desenvolvimento das capacidades sociodiscursivas dos alunos. Além disso, ao promover o ensino-

\footnotetext{
${ }^{1}$ Como o projeto foi ficando cada vez mais conhecido, passamos a chamá-lo de Idiomas para Fins Acadêmicos (IFA), já que o nome oficial (Formação em Línguas para Fins Acadêmicos) era muito longo. Esse nome fantasia - IFA — passou a fazer parte da identidade do projeto.

${ }^{2}$ Neste estudo, optamos em não problematizar conceitualmente o termo "língua estrangeira". Todavia, através dele identificamos a língua francesa e/ou as demais línguas ofertadas pelo IFA. 
aprendizagem das línguas, o projeto assumia uma outra função — a de proporcionar uma prática efetiva de docência para as e os estudantes dos cursos de Licenciatura em Letras da $\mathrm{UFPR}^{3}$.

Desse modo, vinculado às disciplinas de Metodologia e de Prática Docente, ofertadas através do DTPEN, o IFA contava então com a participação de professores em formação - licenciandos, bolsistas e voluntários - para a seleção e organização de conteúdos por módulo a serem trabalhados, a elaboração de materiais didáticos, a aplicação de aulas e a avaliação de aprendizado e desempenho das alunas e dos alunos que eram o público-alvo do projeto. Tal contexto foi a oportunidade de aliar teoria e prática, o que permitiu rever, aprimorar e inovar dinâmicas pedagógicas já cristalizadas, conduzindo para novos modos de ensino-aprendizagem das línguas estrangeiras.

Nessa perspectiva, o Curso de Francês (CF) do IFA buscava atingir as necessidades reais de comunicação dos alunos, na proposta de uma formação em língua francesa para fins acadêmicos. No projeto, o termo "fins acadêmicos" não caracterizava cursos instrumentais voltados única e exclusivamente para o meio universitário, os quais tratariam de ensinar as línguas estrangeiras para a leitura e escrita de textos acadêmicos, como resumos, resenhas, artigos, monografias e seminários. Ainda que também abarcasse essa temática nos níveis mais avançados, o escopo do IFA era mais amplo, abordando temáticas e explorando gêneros discursivos em contextos sociocomunicativos variados. Nas palavras de Picanço (2017, p. 3),

Este Projeto de Extensão [...] busca desenvolver todas as práticas de linguagem, orais ou escritas, a partir de objetivos específicos, neste caso, a inserção do aluno em atividades acadêmicas, em que o uso de uma segunda língua é fundamental. Nossa intenção não é apenas preparar os estudantes para um intercâmbio, mas também para situações e temas que provavelmente encontrariam nessa situação. Os principais objetivos do projeto são: a) permitir que os estudantes de graduação com fragilidade socioeconômica, participem em atividades acadêmicas que exigem o domínio de uma LE, como programas de mobilidade acadêmica internacional, ingresso nos programas de pósgraduação e acesso a obras importantes em suas áreas específicas; b) ampliar os espaços de formação de professores de Língua Estrangeira no curso de Letras da UFPR. Para isso, as atividades são desenvolvidas

\footnotetext{
${ }^{3}$ Chamaremos de professores formadores os professores universitários que coordenavam o projeto, de professores em formação os alunos licenciandos em Letras que atuavam no projeto - seja como bolsistas, voluntários ou em período de estágio, e de alunos e alunas, alunos ou ainda público-alvo, os participantes (estudantes de graduação e de pós-graduação) que recebiam a formação em línguas estrangeiras.
} 
especificamente para os cursos e atividades culturais, como a preparação, discussão e reelaboração de um programa de conteúdos especialmente desenvolvido pelos bolsistas do Projeto.

Retomando, as ações pedagógicas do IFA intencionavam desconstruir dinâmicas pedagógicas já engessadas no ensino-aprendizagem de línguas e, para isso, contavam com a participação dos professores em formação envolvidos. Usamos o termo "dinâmicas pedagógicas engessadas" em referência a uma concepção normativa de ensinoaprendizado de línguas, ou seja, da estrita preocupação com o estudo de conteúdos formais do sistema linguístico (fonética, gramática e léxico), que está, até hoje, extremamente enraizada em nossa cultura, materializada na formação de professores, nos programas de ensino, nos livros didáticos e nas próprias práticas docentes e discentes ${ }^{4}$.

Desse modo, a elaboração dos materiais didáticos, as aulas e a avaliação do ensinoaprendizagem, aliados à constante reflexão teórico-metodológica, eram ações que, no IFA, intencionavam romper com as dinâmicas normativistas que ainda ecoam no espaço escolar, que minimizam a autonomia do professor e que, na maioria das vezes, não dão espaço para o aluno. Assim, os materiais didáticos produzidos pelos próprios professores em formação também representavam, nessa perspectiva, uma alternativa metodológica.

Dito de outro modo, se em cursos tradicionais de línguas o livro didático, apesar de norteador, pode condicionar a ação docente para uma concepção de linguagem e cultura normativista, causando o apagamento da diversidade e dos conflitos inerentes aos embates discursivos da interação humana, nesses aspectos, no IFA, tal dinâmica era desconstruída. Partíamos da ideia de que o professor em formação e o público-alvo eram os atores centrais - aquele com autonomia nas ações pedagógicas e esse como sujeito ativo no aprendizado do idioma.

No IFA, tomávamos como base a perspectiva sociocomunicativa ou sociodiscursiva de linguagem do Círculo de Bakhtin (BAKHTIN, 1992, 1998; VOLÓCHINOV, 2017), que engendra uma abertura conceitual a qual permite o deslocamento para um paradigma sociointeracionista de ensino-aprendizagem de línguas. Nesse paradigma, compreendemos que toda ação pedagógica deva estar centrada no amplo desenvolvimento das capacidades sociocomunicativas e discursivas do aluno. Em outras palavras, consideramos que os alunos podem ir do estrito domínio de regras de funcionamento das línguas, para a elaboração de enunciados discursivos, ou seja, apropriando-se das formas das línguas para construírem discursos críticos e responsáveis,

\footnotetext{
${ }^{4}$ Para um aprofundamento no assunto, ver pesquisas de Picanço (2003; 2017). 
bem situados nos contextos de um mundo globalizado (TILIO, 2013). Nas palavras do pesquisador referenciado,

Em uma abordagem sociointeracional, portanto, aprender uma língua estrangeira significa orientar e sensibilizar o aluno em relação ao mundo multilíngue e multicultural em que vive, conscientizando-o acerca de diferenças culturais e levando-o a respeitar mais o outro e a conhecer melhor a si mesmo, uma vez que é através do olhar do outro que aprendemos a nos conhecer melhor [...]. Além disso, o conhecimento dos discursos em língua estrangeira [...] pode permitir maior acesso aos mais diferentes tipos de conhecimento no mundo globalizado contemporâneo.

Mais do que tornar o indivíduo apto a se comunicar na língua, o acesso a discursos em uma língua também pode servir para empoderá-lo, uma vez que passa a ter acesso a algo que antes desconhecia. De posse desse conhecimento, o indivíduo passa a ter a escolha de tornar-se parte desses novos discursos, tornando-se parte do mundo globalizado. (TILIO, 2013, p. 55-56).

Nessa perspectiva, a exploração pedagógica dos textos multimodais que integravam o repertório de materiais didáticos dos cursos do IFA funcionava como um catalisador da experiência discursiva dos alunos. Tal abordagem era realizada sem perder de vista que os conteúdos trabalhados não viriam desvinculados da realidade de mundo do público-alvo. Desse modo, a sala de aula era compreendida como um espaço de interlocução entre os alunos e o mundo, onde os temas trazidos através dos textos eram discutidos e problematizados. O objetivo principal era inseri-los no diálogo com outras realidades, fazendo-os perceber as nuances discursivas e as tensões ideológicas dos enunciados em língua estrangeira.

A partir desse cenário, na proposta do presente estudo, intencionamos discutir mais de perto aspectos da elaboração dos materiais didáticos do IFA, para verificar suas contribuições a nível teórico-metodológico. Para tanto, retomamos os referenciais teóricos que situam a concepção de linguagem subjacente à elaboração dos materiais didáticos no projeto, mais pontualmente os aspectos centrais do conceito de gêneros discursivos, de enunciado e da noção de dialogismo (BAKHTIN, 1992, 1998; VOLÓCHINOV, 2017). Ainda, servimo-nos dos aportes teóricos da área da Didática de Ensino de Línguas Estrangeiras, mais especificamente dos autores Puren (1988), Cuq e Gruca (2005), Foucambert (1994, 2008), Tilio (2013) e Rojo (2013). 
Nosso objetivo foi realizar uma breve análise qualitativa, interpretativa e documental do programa de formação, dos materiais produzidos no Módulo I do Curso de Francês, durante o ano letivo de 2012 (CF-M1/2012), e de textos diretivos complementares. Esse corpus documental provém do período de atuação como docente (professora de francês em formação) no IFA, em um grupo do CF-M1/2012. Também provém da Memória Reflexiva sobre a prática de ensino e estágio supervisionado, relatório que elaboramos no fim do mesmo ano, no contexto da disciplina de Prática de Docência II, do curso de Licenciatura em Letras Francês da UFPR, sob orientação das professoras Deise Cristina de Lima Picanço e Lívia Fernanda Morales.

Assim, a partir da análise dos materiais didáticos, da revisitação dos documentos agrupados no relatório e da experiência de prática docente, intencionamos revelar pontos importantes relacionados ao uso de textos autênticos e ao modo de estruturação das Unidades Temáticas (UTs) do CF-M1/2012 - inclusive em comparação com a estrutura comum aos livros didáticos de Francês Língua Estrangeira (FLE), que seguem a Abordagem Comunicativa (AC). O ponto crucial da análise trata da exploração pedagógica dos gêneros discursivos, a qual se dividia essencialmente em três etapas: pré-leitura, leitura e pós-leitura. Nessa estrutura, interessa-nos saber como os textos estão didatizados no contexto de elaboração dos materiais didáticos: se consideravam o perfil do público-alvo e os objetivos da formação em línguas estrangeiras do IFA, se desestandardizavam os modos de transmitir conteúdos e se davam privilégio ao estudo sociodiscursivo da linguagem — para além de um estudo limitado aos aspectos formais do sistema da língua (gramática, léxico e fonética).

Cabe esclarecer que o termo "sistema da língua" é aqui compreendido a partir do viés teórico bakhtiniano. Para Bakhtin (1992, 1998) e Volóchinov (2017), o sistema da língua faz parte da linguagem, mas não a define por completo; justamente por ser um sistema, trata-se de uma abstração que não atinge o real funcionamento da comunicação. Desse modo, limitar o trabalho com o texto ao seu código sistêmico sem alcançar sua esfera comunicacional, dos usos desse código como discurso e prática social viva, restringe o aprendizado das línguas, que só se dá, de fato, através dos processos de interação que compõem a nossa experiência socioverbal.

Em suma, formalizar uma análise na temática dos materiais didáticos do CF do IFA pode contribuir para a estruturação de cursos que busquem se inspirar nesta proposta ou que já se assemelhem a ela, seja na UFPR ou em outras instituições de ensino superior. Nesse sentido, o estudo apresentado busca enriquecer o arcabouço de publicações e discutir questões metodológicas relacionadas ao tema; questões que considerem uma 
noção ampla de ensino-aprendizagem de línguas estrangeiras, a partir da perspectiva sociodiscursiva da linguagem, tal como já explicamos.

Nas seções a seguir, a partir do programa do CF-M1/2012, apresentamos a estrutura geral das UTs e seus componentes - tema, situações sociocomunicativas, textos autênticos, conteúdos linguísticos e (inter)culturais, explicando suas funções pedagógicas. Em seguida, descrevemos a abordagem conformada no CF-M1/2012 para a exploração dos gêneros discursivos dos textos autênticos e concluímos com uma breve discussão, considerando as limitações da análise, suas contribuições e comentários adicionais de cunho metodológico que consideramos pertinentes para a avaliação dessa experiência.

\section{AS UNIDADES TEMÁTICAS NOS MATERIAIS DIDÁTICOS DO CURSO DE FRANCÊS DO IFA}

No ano de 2012, cada módulo do CF do IFA era dividido em Unidades Temáticas - cada uma correspondente, em média, a três horas/aula. As UTs eram pensadas para o amplo desenvolvimento sociocomunicativo/sociodiscursivo dos alunos, nos diversos gêneros discursivos que permeiam a vida cotidiana, profissional, estudantil. Alguns exemplos seriam mensagens, bilhetes, entrevistas, canções, artigos, reportagens, resenhas, cartas, receitas, notícias, textos literários e filmes, abarcando, desse modo, um repertório bastante amplo. A estrutura de cada Unidade Temática (UT) estava organizada nos seguintes eixos: tema, situações sociocomunicativas, textos autênticos, conteúdos linguísticos e (inter)culturais, como demonstramos no quadro a seguir: 
Quadro 1: Exemplo de Estrutura da Unidade Temática CF-M1/2012.

\begin{tabular}{|c|c|c|c|c|}
\hline TEMA & $\begin{array}{c}\text { SITUAÇÕES } \\
\text { SOCIOCOMUNICATIVAS }\end{array}$ & $\begin{array}{c}\text { TEXTOS } \\
\text { AUTÊNTICOS }\end{array}$ & $\begin{array}{l}\text { CONTEÚDOS } \\
\text { LINGUÍSTICOS }\end{array}$ & $\begin{array}{l}\text { CONTEÚDOS } \\
\text { (INTER) } \\
\text { CULTURAIS }\end{array}$ \\
\hline $\begin{array}{l}\text { Os estudos } \\
\text { e a vida } \\
\text { prática }\end{array}$ & $\begin{array}{l}\text { *Aspectos socioculturais } \\
\text { relacionados aos gastos } \\
\text { com os estudos na França }\end{array}$ & $\begin{array}{c}\text { *Artigo } \\
\text { escrito, com o } \\
\text { título: } \\
\text { « Faire des } \\
\text { études, ça va } \\
\text { vous coûter } \\
\text { combien ?» }\end{array}$ & $\begin{array}{l}\text { *Os números } \\
\text { *Vocabulário } \\
\text { das despesas } \\
\text { estudantis: } \\
\text { caution, frais } \\
\text { d'agence, frais } \\
\text { d'inscription, } \\
\text { sécurité } \\
\text { étudiante, frais } \\
\text { de matériel } \\
\text { scolaire etc. } \\
\text { *Expressões } \\
\text { relacionadas às } \\
\text { despesas: les } \\
\text { caisses sont } \\
\text { vides, être fauché } \\
\text { etc. }\end{array}$ & $\begin{array}{l}\text { *Informações } \\
\text { (numéricas) } \\
\text { sobre despesas } \\
\text { com a vida } \\
\text { estudantil no } \\
\text { Brasil e na } \\
\text { França }\end{array}$ \\
\hline
\end{tabular}

Fonte: a autora (2020).

Com base no programa do CF-M1/2012, também exemplificamos como seria o modo de organização dos conteúdos para cada um dos componentes - tema, situações sociocomunicativas, textos autênticos, conteúdos linguísticos e (inter)culturais. Para tanto, usamos como exemplo empírico a Aula 5 do programa, que também servirá de referência ao longo de nossa análise, com o objetivo de complementar as discussões realizadas.

$\mathrm{Na}$ sequência, interessa-nos examinar mais de perto cada um dos eixos que estruturam a UT, detalhando suas funções pedagógicas e explicando os modos de organização dos conteúdos. Sendo assim, dividimos a discussão em duas seções: a primeira aborda aspectos teóricos-metodológicos relacionados aos temas e às situações sociocomunicativas e a segunda, aos textos autênticos, aos gêneros discursivos e aos conteúdos linguísticos e (inter)culturais. 


\section{Estrutura das Unidades Temáticas: temas e situações sociocomunicativas}

Na elaboração de uma UT, os professores em formação do CF definiam o tema, individualmente ou em grupo, a partir de algum campo do conhecimento significativo para o público-alvo do IFA (como turismo, história, ecologia, gastronomia, atualidades, educação, trabalho) ou a partir da relação com alguma atividade humana: produção estética (literatura, arte, cinema, teatro, música), atividades comunicativas (jornal, revista, folhetos, rádio), políticas, religiosas, entre outras. Vale ressaltar que o tema não era um item linguístico (gramatical, lexical ou fonético), nem um ato de fala (CUQ; GRUCA, 2005), como ocorria em materiais didáticos pautados na abordagem comunicativa (AC).

Também considerando o perfil do público-alvo do CF, ou seja, alunas e alunos dos cursos de graduação e de pós-graduação da UFPR, os temas escolhidos pelos professores em formação intencionavam explorar textos multimodais - orais, escritos, verbovisuais, sonoro-verbais, presentes nas diversas esferas de comunicação da atividade humana (BAKHTIN, 1992). Mais especificamente, os temas visavam tecer relações com assuntos da vida cotidiana, profissional, universitária e estudantil, aproximando os alunos da realidade sociocultural e sociocomunicativa dos países de língua francesa, numa perspectiva dialógica e intercultural. Vale pontuar ainda que cada módulo de 45 horas contemplava em torno de dez a quinze temas. Além disso, como os temas eram sempre muito mais abrangentes e inesgotáveis, poderiam também estar divididos em subtemas.

Sobre o assunto, Tilio (2013, p. 58) afirma que, no ensino da língua estrangeira, a escolha de temáticas deve estar relacionada aos aspectos da variação linguística da língua e da pluralidade cultural. Também, sobre o papel dos temas no ensino da língua estrangeira, o pesquisador faz considerações muito relevantes para o contexto do CF do IFA:

Para alcançar o objetivo sociointeracional de efetivamente permitir que o aprendiz atue no mundo usando a língua estrangeira, é fundamental que os conteúdos temáticos propostos propiciem seu engajamento discursivo. Ao oferecer temas familiares, que "digam algo" ao aluno, e relevantes aos seus contextos situacionais e culturais, cria-se uma oportunidade real para que ele se engaje sociodiscursivamente no processo de ensino e aprendizagem, o que propicia a construção de uma base de conhecimento sólida na língua estrangeira. [...]

Por isso, é importante que os conteúdos temáticos partam de conhecimentos, ideias e prática socioculturais que não causem estranhamento, podendo ter sido experimentados ou apenas 
potenciais, mas dentro da realidade e possibilidades do aprendiz. (TILIO, 2013, p. 59).

Seguindo tal perspectiva, para cada proposta temática eram definidas situações sociocomunicativas, como: os estudos universitários e suas implicações na rotina dos estudantes, situações de formalidade e informalidade na vida cotidiana na França e a diversidade de sotaques em países de língua francesa. Aqui, é essencial não confundir as situações sociocomunicativas do IFA com as noções e funções ou situações comunicativas da AC, como: se apresentar, falar da rotina, contar sua história de vida, falar de seus projetos para o futuro etc.

Nesse sentido, é importante relembrar que a AC surgiu no fim da década de 1970, com o objetivo principal de conduzir o ensino-aprendizado de línguas para o desenvolvimento de uma competência comunicativa (TILIO, 2013). Inicialmente chamada de nocional-funcional (PUREN, 1988), a AC preconizava que, para saber se comunicar na língua estrangeira, o falante deveria saber manejar os enunciados linguísticos em adequação com a situação e a intenção de comunicação presentes em cada função da linguagem ou ato de fala (CUQ; GRUCA, 2005). Vale ressaltar que a AC marcou toda uma geração de programas de cursos de idiomas, de materiais de ensinoaprendizado de línguas e de cursos de formação docente.

Trazemos aqui o exemplo do método Reflets 1, livro didático de Francês Língua Estrangeira (FLE), que adota a $\mathrm{AC}$ que, no quadro de conteúdos, mostra bem a relação entre as situações comunicativas e os atos de fala. Na Figura 1 é possível observar que para cada situação são elencados uma série de atos de fala, como no DOSSIER 0, em que a situação é "encontros" e "apresentação" e os atos de fala são "cumprimentar alguém, se apresentar, perguntar e dizer o sobrenome e o nome, indicar a nacionalidade, contar, soletrar". Esse é um aspecto bastante comum dos livros didáticos ditos comunicativos, em que a progressão dos conteúdos a serem aprendidos não se organiza pela progressão de conteúdos gramaticais, como nas abordagens anteriores, mas a partir de noções e de funções ou de atos de fala - normalmente definidos através de um verbo de ação (apresentar-se, perguntar, contar etc.). 
Figura 1: Quadro de conteúdos do método Reflets 1.

\begin{tabular}{|c|c|c|c|c|c|c|}
\hline & DOSSIER 0 & DOSSIER 1 & D055IFR $\mathbb{Z}$ & DOSSIER 3 & DOSSIER 4 & DOSSIER 5 \\
\hline 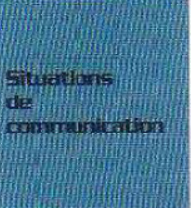 & $\begin{array}{l}\text { - rencontres } \\
\text { - présentations }\end{array}$ & $\begin{array}{l}\text { rochorcho d'un } \\
\text { colocataire } \\
\text { - visite d'un } \\
\text { appartement }\end{array}$ & $\begin{array}{l}\text { - accueil d'uns cliente } \\
\text { d'une agence de } \\
\text { voyages } \\
\text { - rapports amicaux et } \\
\text { professionnels entre } \\
\text { collogguos }\end{array}$ & $\begin{array}{l}\text { - enquête sur les } \\
\text { occupations des gens } \\
\text { - renccntre ḋ un } \\
\text { vernissage }\end{array}$ & $\begin{array}{l}\text { - discussion sur les } \\
\text { noyens de transport } \\
\text { en cas de protlème } \\
\text { - entrevue avec un } \\
\text { direcieur de centre } \\
\text { sulturel } \\
\text { - présentation du } \\
\text { sentre }\end{array}$ & $\begin{array}{l}\text { - à propos d'un } \\
\text { comportement } \\
\text { inthubiluel qu suscile } \\
\text { la curiosité } \\
\text { - accuel d'un visiteur } \\
\text { étranger et discussion } \\
\text { d'Ln programme de } \\
\text { vistes. }\end{array}$ \\
\hline $\begin{array}{l}\text { Notions, } \\
\text { actes de parole }\end{array}$ & $\begin{array}{l}\text { - saluer quelqu'un } \\
\text { - se présenter } \\
\text { - demarder et dire le } \\
\text { nom et le prénom } \\
\text { - indiquer la tratiunialilé } \\
\text { compter } \\
\text { - épeler }\end{array}$ & $\begin{array}{l}\text { - saluer et employer } \\
\text { das fomules de } \\
\text { politesse } \\
\text { - se p'ésenter } \\
\text { - indicuer une azresse } \\
\text { - exprmer } \\
\text { l'appatenence } \\
\text { - idenifier quelcu'un } \\
\text { - demander et donner } \\
\text { son accord }\end{array}$ & $\begin{array}{l}\text { - distinguer le } \\
\text { tutoiement et } \theta \\
\text { vourniermant } \\
\text { - interroçer sur les } \\
\text { personnes et les } \\
\text { choses } \\
\text { - indiquer le tut et la } \\
\text { destination } \\
\text { - demander à } \\
\text { quelqu'un de faire } \\
\text { quelque chose } \\
\text { - aocepter et refuser } \\
\text { - exprimer son } \\
\text { appréciation, 'aire des } \\
\text { conpliments } \\
\text { - indiquer la cate } \\
\text { - demander une } \\
\text { explication } \\
\text { - s'informer sur la } \\
\text { façcn de payer }\end{array}$ & $\begin{array}{l}\text { - demender et donner } \\
\text { des informations } \\
\text { personnelles } \\
\text { - demander et dre la } \\
\text { netionalité } \\
\text { - décrire una personne } \\
\text { et la désigner } \\
\text { - dire ce qu'on fait } \\
\text { - demander et dre } \\
\text { d'vù un vient } \\
\text { zxprimor doe goute } \\
\text { et des prétérences } \\
\text { - demander et donner } \\
\text { des raisons }\end{array}$ & $\begin{array}{l}\text { - demander et donner } \\
\text { des informations sur } \\
\text { les transports } \\
\text { - demander et dire où } \\
\text { on va } \\
\text { - exprimer la présence } \\
\text { ou l'absence } \\
\text { - parler d'événements } \\
\text { passés } \\
\text { - parler d'événements } \\
\text { proches cu d'intentons } \\
\text { - exprimer des } \\
\text { concitlons } \\
\text { - rassurer quelqu'un } \\
\text { - exprimer des goûts } \\
\text { - attirer l'attention de } \\
\text { quelqu'un } \\
\text { - dire l'heure }\end{array}$ & 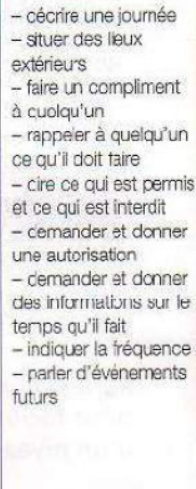 \\
\hline
\end{tabular}

Fonte: Capelle e Gidon (1999, p. 4).

Dentre os princípios da AC estão o uso de materiais autênticos, a contextualização da frase para além dos aspectos linguísticos ou gramaticais, o foco nas quatro competências - produção oral e escrita, compreensão oral e escrita e a estratégia de direcionar o ensino-aprendizado da língua para um público-alvo (crianças, adolescentes, adultos) ou para um objetivo de aprendizado específico (profissional, jurídico, acadêmico, entre outros) (PUREN, 1988; CUQ; GRUCA, 2005). Ainda que alguns desses princípios também estejam presentes na estrutura do CF-M1/2012 do IFA, a saber: o uso de textos autênticos e o enfoque nos interesses de aprendizado do público-alvo, o termo "situações sociocomunicativas" é entendido a partir de outro paradigma teórico-metodológico.

Sendo assim, quando falamos em situações sociocomunicativas no contexto do IFA, falamos de situações sociais que aproximam o aluno da diversidade linguística, cultural e ideológica que permeia os discursos dos sujeitos que interagem na língua estrangeira estudada. Trata-se de situações que estão vinculadas a diferentes realidades de mundo e que revelam, através das formas de uso da língua, posicionamentos ideológicos, políticos e econômicos diversos; cabe ressaltar, ainda, que elas vão além da diversidade linguística no sentido de sua variação lexical, fonética ou sintática, estando sobretudo vinculadas aos falantes - sujeitos sócio-historicamente situados. 
Anteriormente, no Quadro 1, buscamos demonstrar como o tema de cada UT estava vinculado à situação sociocomunicativa, ou seja, dentro do grande tema os estudos e a vida prática, havia a situação sociocomunicativa atrelada, os aspectos socioculturais relacionados aos gastos com os estudos na França. Outras situações poderiam ser abordadas e o ideal seria sempre organizá-las de modo coerente, ou seja, em sua relação com os conteúdos a serem trabalhados. Nesse caso não havia regra prévia: tudo dependia dos objetivos fixados e da adaptação aos interesses de aprendizado dos alunos que, na perspectiva sociodiscursiva, são colocados como os atores centrais dos processos de ensino-aprendizagem. Desse modo, tendo como base os conteúdos do Quadro 1, para um grupo de futuros alunos intercambistas, poderíamos imaginar uma segunda situação sociocomunicativa: modalidades de bolsas de estudos na França.

Vale pontuar ainda que, para estruturar uma UT, era ideal considerar a carga horária total de cada módulo do curso (45 horas) e a média de três horas/aula estipuladas para cada UT. Do mesmo modo, era recomendado integrar um número conveniente de textos autênticos, dependendo dos objetivos determinados e da extensão dos textos, para não sobrecarregar o tema com situações sociocomunicativas ou com textos pouco explorados.

\section{Estrutura das Unidades Temáticas: materiais autênticos, gêneros discursivos e con- teúdos linguísticos e (inter)culturais}

No CF do IFA, os materiais didáticos eram estruturados a partir de textos autênticos multimodais ${ }^{5}$ provenientes de meios de comunicação diversos como: livros, revistas, rádio, TV e sobretudo da internet. Ao contrário dos textos didáticos redigidos em função de critérios pedagógicos, os ditos autênticos (de natureza multissemiótica ou multimodal) são elaborados com fins de comunicação real e não exclusivamente em vista do aprendizado de uma segunda língua (CUQ; GRUCA, 2005, p. 431-432). Isso porque são enunciados produzidos em situações reais da comunicação humana e que circulam na vida cotidiana, familiar, profissional, estudantil etc.

De acordo com Puren (1988, p. 171), os textos autênticos se popularizaram nos livros didáticos de metodologia audiovisual a partir da década de 1970, justamente como uma reação contra os textos elaborados artificialmente, já que o objetivo era o de colocar o aluno em contato com a língua real e ensinar aspectos da cultura. No entanto, na transposição didática, ao serem integrados nos materiais de ensino, eles acabam tendo

\footnotetext{
${ }^{5}$ Entende-se o termo "multimodais" a partir da definição de Rojo (2013), ou seja, são textos que envolvem diversas linguagens, mídias e tecnologias.
} 
sua natureza enunciativa deturpada ao se tornarem apenas um suporte facilitador para a compreensão de conteúdos linguísticos, geralmente pautados na gramática normativa e nas formas da língua padrão. Desse modo, mesmo que os textos autênticos também estejam presentes nos livros didáticos de línguas estrangeiras, a abordagem tradicional de sua exploração pedagógica acaba limitando o desenvolvimento do aluno como um sujeito crítico, capaz de se apropriar da língua estrangeira de modo amplo — em suas nuances linguísticas, discursivas e culturais (VAILATTI, 2016).

No entanto, em qualquer projeto de ensino-aprendizado de línguas é inevitável que os textos autênticos, quando didatizados, também passem a ter uma função pedagógica. É como se perdessem a correspondência direta com seu contexto de origem e passassem a corresponder a outro, ao contexto escolar. Diante desse cenário, a proposta do CF foi a de encontrar caminhos alternativos para a elaboração de materiais didáticos que respondessem de forma mais adequada à formação discursiva e crítica dos alunos, atentando para os contextos sociocomunicativos atuais - de globalização e de modos de interação cada vez mais intermediados pelas mídias sociais. Em outras palavras, a questão norteadora, para os professores em formação, consistia em aprender a explorar pedagogicamente os textos autênticos na perspectiva da abordagem sociodiscursiva, de modo que eles pudessem veicular os sentidos das situações socioculturais abordadas e dialogar com as realidades de mundo dos alunos.

Como dito anteriormente, a concepção de linguagem subjacente à elaboração dos materiais didáticos estava situada na teoria bakhtiniana, mais especificamente nos conceitos de enunciado e de gêneros do discurso (BAKHTIN, 1992, 1998). Nesse sentido, os textos autênticos eram compreendidos como gêneros, ou seja, como tipos relativamente estáveis de enunciados discursivos, pertencentes ao fluxo da comunicação nos mais diversos contextos que permeiam as esferas da atividade humana ${ }^{6}$ (BAKHTIN, 1992).

Cabe observar que tal base teórica permitiu compreender o princípio comunicativo dos gêneros discursivos multimodais (ROJO, 2013), que também integravam o escopo de materiais autênticos do CF. Nessa perspectiva, a ideia era abarcar uma variedade de linguagens e discursos, desde os gêneros mais simples que se constituem de uma comunicação verbal mais espontânea e imediata e que estão diretamente ligados à comunicação cotidiana, como os bilhetes, as notas, as réplicas de diálogo, as mensagens,

\footnotetext{
${ }^{6}$ Os gêneros do discurso são definidos como tipos relativamente estáveis de enunciados no sentido de que há uma estabilidade no gênero, pois ele guarda um conjunto de características próprias, mas ela é relativa, pois varia em função da atividade interacional, da esfera de atividade humana e ao longo do tempo. (BAKHTIN, 1992).
} 
até os gêneros mais elaborados, que têm um propósito de interlocução mais amplo e se constituem no âmbito das esferas sociais complexas da comunicação, como a artística, a política, a literária e a científica? ${ }^{7}$.

Assim, retomando a teoria bakhtiniana, os enunciados discursivos produzidos em língua estrangeira pelos falantes em interação assumem então as formas relativamente estáveis que caracterizariam o perfil de determinados gêneros, como os supracitados. Por estarem em relação dialógica com outros enunciados, não estão restritos aos limites da língua como sistema pois, de modo mais amplo, integram o fluxo da comunicação veiculando sentidos e valores diversos, visões de mundo e ideologias (BAKHTIN, 1992, 1998).

Para Bakhtin (1992), a formação de novos gêneros está sempre condicionada ao aparecimento de novas situações de interação da vida social que, por sua vez, têm finalidades discursivas específicas. Assim, se os gêneros nunca são formatos fixos, ou seja, se são um repertório infinito e heterogêneo em constante derivação e hibridização, em que o discurso está sempre se moldando às novas situações de comunicação, encontramos na estrutura hipertextual da internet novos gêneros discursivos e, consequentemente, novas formas de leitura e escrita (ROJO, 2013, p. 20).

Por essa razão, a partir da análise do programa do CF-M1/2012, verificamos quais eram os gêneros discursivos que integravam o repertório do curso, indagando se eram multimodais, se estavam restritos às mídias impressas, se estavam presentes nos ambientes virtuais, se circulavam exclusivamente nestes ambientes ou, ainda, em ambos os espaços. À primeira vista, percebemos um repertório abrangente de gêneros multimodais, como as publicidades, as canções, os filmes, além dos gêneros que circulam exclusivamente na internet e em meios impressos, tal como listamos no Quadro 2 a seguir:

\footnotetext{
${ }^{7} \mathrm{Na}$ conceituação bakhtiniana (BAKHTIN, 1992), os gêneros do discurso estão divididos em dois grandes grupos: primários e secundários.
} 
Quadro 2: Gêneros discursivos do Programa do CF-M1/2012.

\begin{tabular}{|c|}
\hline GÊNEROS DISCURSIVOS DO PROGRAMA DO CF-M1/2012 \\
\hline *Entrevistas de TV e rádio disponíveis na internet (YouTube e redes sociais) \\
*Reportagens de TV e rádio disponíveis na internet (YouTube e redes sociais) \\
*Publicidades/ propagandas da TV disponíveis no YouTube \\
*Artigos (científicos ou não) disponíveis na internet (em sites diversos) \\
*Entrevistas escritas disponíveis na internet (em sites diversos) \\
*Reportagens escritas disponíveis na internet (em sites diversos) \\
*Textos escritos que circulam exclusivamente na internet: blogs, fóruns, comentários em \\
redes sociais etc. \\
*Trechos de filmes \\
*Canções e clipe de canções disponíveis no Youtube \\
*Fragmentos de textos literários exclusivamente escritos (romance, conto, poesia etc.) \\
\hline
\end{tabular}

Fonte: a autora (2020).

Através de uma observação mais atenta do programa do M1, percebemos que a maior parte dos gêneros discursivos multimodais selecionados no CF são provenientes da internet, apesar de também circularem em outras mídias, como jornais televisivos e rádio. Notamos, ainda, que os gêneros exclusivamente escritos (artigos, entrevistas, reportagens) encontram-se também disponíveis na internet, em sites francófonos. Sobre os gêneros discursivos ditos secundários na conceituação bakhtiniana, verificamos as canções, os filmes (longa e curta-metragem) e os textos literários.

No entanto, não foi possível perceber uma expansão para outras linguagens como a pintura, a fotografia, a dança ou então, as histórias em quadrinhos (consideradas uma linguagem verbo-visual). Nesse sentido, pensamos que a escolha do repertório estaria motivada pela centralidade que ocupa o elemento verbal na natureza composicional dos gêneros discursivos identificados. Sobre este aspecto, é natural que o componente verbal ocupe tal posição; mas, numa perspectiva ampla de letramento, também seria interessante ampliar o escopo para outras formas de linguagem e colocá-las em diálogo com outros enunciados nos contextos das situações sociocomunicativas previstas para cada tema de UT.

Vale pontuar ainda que os gêneros discursivos multimodais, como os que integram o repertório do CF, são constituídos de enunciados multissemióticos (ROJO, 2013, p. 24), ou seja, os elementos verbais, visuais, sonoros, gestuais diluem-se em enunciados verbo-visuais, sonoro-visuais, sonoro-verbais, verbo-gestuais, a partir das infinitas 
possibilidades de associação entre os elementos, que se articulam indissociavelmente na construção de sentidos. Desse modo, ainda que o elemento linguístico ocupe um papel central no contexto de ensino-aprendizagem da língua estrangeira, no trabalho pedagógico com gêneros discursivos híbridos não há como estudá-lo ou interpretá-lo isoladamente. Por isso, é primordial não promover a sobrevalorização do elemento verbal em relação aos outros, pois isso pode resultar na hierarquização de uma materialidade sobre as outras, tornando-as artificialmente periféricas ou suportes para a compreensão de conteúdos linguísticos (ROJO, 2013; VAILATTI, 2016).

Partindo da análise do programa do CF-M1/2012 foi possível perceber que o leque diversificado de gêneros discursivos que integravam o escopo do CF buscava ampliar o repertório discursivo dos alunos, o que implicava também na preocupação em fazer com que os conteúdos fizessem sentido para a realidade desses sujeitos, que ultrapassassem o mero caráter de conteúdos escolares, noção similar à de desescolarização da leitura de Foucambert $(1994,2008)$. Na perspectiva do autor, o aprendizado da língua estrangeira deveria funcionar como um catalisador da experiência discursiva do aluno, fazendo-o criar recursos para acionar seus conhecimentos de contexto, de mundo e de ordem extralinguística para interagir com os discursos, indo das formas aos sentidos, minimizando a aparente inteligibilidade da língua estudada.

Desse modo, a preocupação era a de não cortar os fios da comunicação ao tratar dos discursos, para que fosse possível promover a interação socioverbal de modo efetivo e não de modo mecânico ou artificializado. Os materiais didáticos elaborados, na mesma perspectiva, buscavam privilegiar a interação através de discussões, debates, comentários, expressão de pontos de vista e opinião a fim de promover a formação do aluno como um sujeito discursivo e crítico, oferecendo-lhe então, as ferramentas necessárias para que ele pudesse se tornar mais íntimo das formas da língua estrangeira estudada e assim, se inserir progressivamente e com autonomia nos campos discursivos da comunicação.

Partindo então do viés teórico bakhtiniano (BAKHTIN, 1992, 1998; VOLÓCHINOV, 2017), compreende-se que o estudo do enunciado discursivo, para além do enunciado linguístico, busca levar o aluno a reconhecer a significação das formas da língua no contexto da comunicação, considerando as nuances da diversidade linguística e suas marcas culturais e ideológicas nas singularidades de cada contexto. Além disso, busca torná-lo capaz de produzir enunciados mobilizando seus conhecimentos linguísticos e efetuando escolhas - gramaticais, lexicais e fonológicas — para elaborar o seu discurso particular. 
$\mathrm{Na}$ abordagem dos conteúdos (interculturais), a estrutura de cada UT objetivava criar um espaço interlocutivo e intercultural capaz de mobilizar a atitude responsiva ativa dos alunos em relação aos discursos, para que eles pudessem se expressar sobre suas próprias culturas e as do outro, possibilitando assim a reflexão em torno das imagens identitárias. $\mathrm{O}$ objetivo consistia em fazer perceber a existência da heterogeneidade que compõe cada uma das culturas de língua francesa, a fim de também desconstruir uma visão estereotipada da língua estudada.

Como a análise do programa do CF-M1/2012 pôde mostrar, a opção por textos autênticos de gêneros discursivos multimodais se fez predominante e, consequentemente, trouxe consigo implicações pedagógicas que devem ser foco de nossas preocupações e reflexões. Tratamos de fazer considerações bastante amplas e breves, mas que já desenharam o perfil dos materiais didáticos do CF do IFA. Na seção a seguir, descrevemos as etapas adotadas para a exploração dos gêneros discursivos através dos materiais autênticos.

\section{ABORDAGEM DOS GÊNEROS DISCURSIVOS NA UNIDADE TEMÁTICA}

$\mathrm{Na}$ discussão realizada anteriormente, foi possível perceber que os materiais autênticos do CF-M1/2012 buscavam integrar uma variedade de gêneros discursivos, que circulam em meios de comunicação distintos (TV, rádio, revista, livro, internet etc.). Retomando o exemplo do Quadro 1, como material autêntico, foi selecionado um documento de um site especializado na divulgação de informações e na orientação sobre formação e conclusão de estudos universitários, chamado letudiant.fr ${ }^{8}$. Como é possível observar na Figura 2, trata-se de um texto escrito autêntico, de natureza essencialmente informativa, com um registro de linguagem padrão, que traz informações numéricas relativas aos custos da vida estudantil na França.

\footnotetext{
${ }^{8}$ Texto autêntico: «Faire des études, ça va vous coûter combien ? ». Disponível em: https://www. letudiant.fr/cout-des-etudes.html. Acesso em: 16 nov. 2020. O conteúdo disponibilizado através deste endereço eletrônico é constantemente atualizado, portanto não corresponde exatamente ao texto original utilizado na aula 5 do CF-M1/2012.
} 
Figura 2: Trecho do material autêntico do CF-M1/2012 - AULA 5. DOSSIER : LE VRAI PRIX DES ÉTUDES

Etudiant = fauché ? Une équation courante. Trop courante... On a cherché à évaluer combien vous coûteraient vos études, quels que soient votre cursus, votre niveau social ou votre mode d’hébergement.

\section{Faire des études, ça va vous coûter combien ?}

Argent, (toujours) trop cher

C'est un exercice obligé : à chaque nouvelle rentrée, les syndicats étudiants calculent et recalculent les dépenses incontournables de la rentrée. Ainsi d'après l'UNEF, le coût de la vie devrait être 5,9 \% plus cher que l'année dernière. Pour la FAGE, la rentrée universitaire a augmenté de 3,5\% par rapport à 2007. La Confédération étudiante, quant à elle, annonce une augmentation de $3,7 \%$. Si les estimations peuvent donc varier (voir cidessous), tous font le même constat : être étudiant aujourd'hui, ça coûte cher !

Surtout quand on devient autonome : si on ajoute, bout à bout, le prix du loyer, les repas, la connexion Internet/téléphone, les transports, les loisirs, et plus encore... il faut compter grosso modo pour un étudiant vivant seul un budget mensuel de 600-800 € en province et de 950-1200€ à Paris. Un écart persistant donc Parisprovince, même si la FAGE observe une plus forte augmentation du coût de la vie en province $(+4,7 \%)$ qu'en région parisienne $(+2,3 \%)$.

\section{Sale mois de septembre}

Après avoir payé les deux mois de caution, les frais d'agence, les frais d'inscription, la sécurité étudiante... les caisses sont vides. Le mois de septembre est un gouffre ! "La rentrée de trois étudiants sur quatre se fait avant le 15 septembre. Or, les étudiants ne percevront pas leurs bourses avant le mois d'octobre ou novembre. Septembre est le mois de toutes les galères avec un coût variant de $700 €$ à $2100 €$ ", assure I'UNEF.

\section{Combien faut-il prévoir alors ?}

A chaque calcul ses imperfections. Comment définir le "minimum vital" d'un étudiant aujourd'hui ? Les deux grandes études de I'UNEF et de la FAGE ne donnent pas la même réponse. Voici résumées leurs estimations... ainsi que la nôtre!

\section{Estimation de la FAGE}

Le syndicat étudiant a décidé de faire un "focus" sur le mois de la rentrée. Son "indicateur de rentrée" se décompose entre, d'une part, les frais de vie "habituels" de l'étudiant et, d'autre part, les frais "exceptionnels" liés à l'installation (caution, inscription à la fac, sécurité sociale, complémentaire santé, frais de matériel scolaire)

Budget mensuel (mois de rentrée) d'un étudiant en licence, non-boursier, vivant seul en location

\begin{tabular}{|l|l|l|}
\hline & Paris & Province \\
\hline Sous-total frais exceptionnels de rentrée & $1765,53 €$ & $1459,53 €$ \\
\hline Sous-total de vie & $1169,64 €$ & $975,80 €$ \\
\hline Total pour le mois de rentrée & $2935,17 €$ & $2425,33 €$ \\
\hline
\end{tabular}

Source : L'indicateur du coût de la rentrée 2008/2009, La FAGE, septembre 2008.

Fonte: Site da internet: letudiant.fr (2012) ${ }^{9}$.

\footnotetext{
${ }^{9}$ Disponível em: https://www.letudiant.fr/cout-des-etudes.html. Acesso em: 16 nov. 2020. 
$\mathrm{Na}$ exploração pedagógica dos textos autênticos (como o da Figura 2), era feito um trabalho dividido em três etapas: pré-leitura, leitura e pós-leitura. A chamada préleitura pode ser compreendida como uma sensibilização ou aproximação ao gênero discursivo em questão. Desse modo, eram formuladas perguntas de compreensão global, direcionadas ao gênero discursivo que conforma o texto, tais como: qual o tema, em que tipo de atividade social normalmente se produz o texto, qual é sua função social (informar, debater, comentar, convencer, alertar, instruir, entreter, divertir, criticar, ensinar, vender), quais são suas características organizacionais gerais (layout ou mise en page), quem é o público leitor ou público alvo (crianças, adolescentes, estudantes, trabalhadores, adultos), em que meio de comunicação é veiculado (rádio, TV, revistas, jornais, internet), quem produziu, onde e quando foi produzido.

Vale ressaltar que, para o trabalho com textos multimodais, os professores em formação formulavam questões específicas relacionadas aos aspectos composicionais do gênero - integrando, por exemplo, a leitura de elementos visuais, sonoros e gestuais. As respostas poderiam ser dadas oralmente pelos alunos, mas as perguntas deveriam aparecer na exploração pedagógica dos materiais.

Após uma primeira aproximação, na etapa de leitura, o gênero era explorado a partir de seus conteúdos sociodiscursivos, linguísticos e culturais. Em outras palavras, depois de ter uma visão global do documento, o aluno era levado a uma compreensão mais detalhada do texto, ou seja, de reconstituição da informação, de interpretação das ideias de cada parágrafo ou trecho, de estabelecimento de relações contextuais - entre os discursos contidos no texto e as realidades de mundo, de apreensão de julgamentos, valores e opiniões.

Se no paradigma sociointeracionista de ensino-aprendizagem o conhecimento da língua se constrói a partir da interação com os gêneros discursivos (TILIO, 2013), a materialidade linguística dos enunciados era então explorada através da elaboração de questões escritas, em francês, as quais os alunos responderiam por escrito ou oralmente, atentando para o fato de que seriam questões de uso da linguagem e não de suas nomenclaturas (observar os tópicos para os conteúdos linguísticos no Quadro 1).

Nessa perspectiva, eram perguntas que não deixavam de explorar os tempos verbais e os verbos; os diferentes pronomes (pessoais, demonstrativos, possessivos, indefinidos, relativos); os artigos (definidos, indefinidos); os conectores, incluindo preposições, conjunções e advérbios; as pontuações (aspas, ponto, ponto e vírgula, ponto de interrogação, travessão); e, ainda, os vocabulários - transparentes e opacos em relação ao português brasileiro - a língua materna da maioria dos alunos do IFA. 
Aqui, citamos mais especificamente os conteúdos linguísticos, mas em se tratando de textos orais, sonoros e imagéticos, há ainda uma infinidade de conteúdos que poderiam ser explorados.

Nesse sentido, reiteramos que, na perspectiva bakhtiniana, as formas das línguas estão em constante derivação, renovação e evolução para dar conta de responder às sempre novas situações discursivas (BAKHTIN, 1992, 1998; VOLÓCHINOV, 2017). A variabilidade e mutabilidade das formas são tão infinitas quanto o próprio repertório de gêneros discursivos, que inclusive podem se combinar, se hibridizar, se mesclar dentro de um mesmo documento, conforme os contextos das situações discursivas que os configuram (ROJO, 2013).

Textos essencialmente informativos, como os do exemplo da Figura 2, possuem seus próprios recursos para materializar o discurso, textos literários vão possuir outros, histórias em quadrinhos, na associação entre o verbal e o visual, outros ainda, as canções vão materializar sentidos não apenas em palavras, mas também em melodias. É importante considerar a especificidade composicional de cada gênero discursivo a fim de determinar como podem ser explorados pedagogicamente os seus elementos constitutivos, sem perder de vista que eles estão sempre se combinando na intenção de veicular sentidos.

Quanto mais eficaz for a exploração pedagógica do gênero, mais conhecimentos o aluno vai poder adquirir em relação aos recursos gramaticais, lexicais e fonéticos da língua, mais íntimo vai se tornar das formas da língua e de como elas atuam na construção de sentidos. Do mesmo modo, esse aluno terá mais facilidade de mobilizar os seus próprios recursos linguísticos para construir o seu discurso individual. Como no remate para tal exploração, poderíamos pensar no uso de paráfrases, reescritas, reformulações, substituições, associações, explicações para praticar tais conteúdos ${ }^{10}$.

Finalmente, na etapa de pós-leitura, a ideia, nas UTs do curso, era ampliar o ponto de vista do texto sobre o tema em geral e promover a reflexão, a discussão, o debate e a pesquisa intercultural através de questões orientadas, considerando que estes aspectos também estão fundamentados na vivência e na realidade de mundo do aluno (observar o tópico para os conteúdos culturais no Quadro 1). Geralmente, na etapa de pós-leitura o aluno realizava uma atividade de produção, um texto a partir do gênero ou do conteúdo trabalhado e a partir de reflexões individuais e/ ou coletivas que envolvessem pesquisa ou não.

\footnotetext{
${ }^{10}$ Para um aprofundamento na questão, sugerimos as seguintes referências: Nery (2003) e Antunes (2007).
} 
A atividade de pós-leitura, vinculada ao texto autêntico do site letudiant.fr (Figura 2), consistia em escrever um comentário descrevendo as despesas pessoais relacionadas aos estudos superiores e construir um quadro indicativo dos valores de cada despesa ${ }^{11}$. $\mathrm{Na}$ exploração pedagógica da atividade estava prevista uma discussão em grupo - em francês ou em português - para o compartilhamento destas informações relacionadas aos custos da vida estudantil.

Para concluir, vale ressaltar que não era obrigatório esgotar a exploração das três etapas - pré-leitura, leitura e pós-leitura - em todos os gêneros trabalhados na UT. A principal preocupação era a de manter uma coerência interna em relação aos tópicos e objetivos definidos para cada componente da UT (tema, situações sociocomunicativas, textos autênticos, conteúdos linguísticos e culturais). Todavia, todos os gêneros deveriam ser explorados em alguma destas etapas, seja na pré-leitura, na leitura ou na pós-leitura.

\section{CONSIDERAÇÕES FINAIS}

De modo geral, em relação ao uso prático dos materiais didáticos em sala de aula, ainda que tenha sido possível perceber fragilidades e limitações na exploração de textos autênticos de diferentes gêneros discursivos, é preciso lembrar que esse uso envolvia o trabalho de professores em processo de formação, que também estavam em busca da experiência e da vivência necessárias para elaborar os materiais, mediar as discussões, enfim, conduzir o trabalho pedagógico como um todo. Nesse sentido, mesmo que buscassem materializar uma abordagem sociointeracionista de ensino-aprendizado da língua através de suas ações, muitas vezes, ainda não compreendiam plenamente os próprios paradigmas de tal abordagem.

Nesse sentido, pensando nas reflexões introdutórias deste estudo, relacionadas à tradição normativista de ensino de línguas e à dificuldade de romper com tal paradigma, a partir de nossa experiência no $\mathrm{CF}$ pudemos constatar que, mesmo que o trabalho com os gêneros discursivos não fosse apenas pretexto para o estudo dos aspectos linguísticos do idioma estudado, havia uma grande tentação em escolher os documentos autênticos a partir dos conteúdos gramaticais, lexicais e fonéticos que eles pudessem oferecer em detrimento dos sentidos dos discursos contidos nesses documentos. Tal motivação, ainda

\footnotetext{
${ }^{11}$ Enunciado da atividade de pós-leitura: Et vous ? Combien dépensez-vous pour vos études supérieures?

Construisez un tableau et écrivez un petit texte en décrivant vos dépenses.

Tradução nossa: E você? Quanto você gasta em seus estudos superiores? Construa um quadro e escreva um pequeno texto descrevendo suas despesas.
}

Revista X, v. 16, n. 4, p. 1038-1061, 2021. 
que nem sempre consciente, muitas vezes culminou em um tipo de transposição didática dos textos autênticos que poderia ser qualificada como mecânica ou simplificada. $\mathrm{Na}$ prática, seria como usar um documento de previsão do tempo para trabalhar o futuro simples, usar uma receita culinária para trabalhar o imperativo.

Consideramos importante chamar a atenção para o risco dessa armadilha. Em contrapartida, admitimos que é uma tarefa árdua encaixar um texto autêntico em uma progressão coerente dentro de um programa de ensino, pois isso requer a habilidade do professor em saber explorá-lo com eficiência. Muito embora a tendência docente seja a de optar por caminhos mais conhecidos (conhecidos de abordagens mais tradicionais inclusive, como a tradicional, a audiovisual, entre outras), é preciso que o olhar do professor também aprenda a mudar de paradigma, no sentido de lembrar que há um repertório infinito de gêneros que podem ser explorados a partir de diferentes perspectivas e que praticamente não existe documento autêntico perfeitamente adequado para cada objetivo pedagógico.

Em todo caso, através da experiência no CF-M1/2012, constatamos que a exploração de gêneros discursivos variados requer um trabalho pedagogicamente conduzido e que grande parte desse trabalho acontece na etapa anterior ao momento de aplicação das aulas, ou seja, durante a elaboração dos materiais didáticos. Tal aspecto nos faz perceber importância desta etapa para o contexto geral de gestão de um projeto como o IFA, bem como para qualquer outro projeto de ensino-aprendizado de línguas, que compreenda, naturalmente, a elaboração de materiais, a aplicação de aulas e a avaliação do aprendizado.

Comparando com outras formas de organização de conteúdos em materiais didáticos, mais pontualmente em referência aos livros didáticos de FLE de AC, salientamos alguns aspectos importantes a serem levados em consideração na elaboração de materiais, de modo que eles possam efetivamente se constituir como uma alternativa metodológica, melhor respondendo aos pressupostos do paradigma sociointeracionista: (1) optar por temas com os quais o público-alvo já tenha intimidade ou algum conhecimento prévio; (2) optar por materiais autênticos que possam promover situações de uso da língua estrangeira mesmo nos níveis mais iniciantes; (3) buscar estratégias de exploração destes materiais que possibilitem a entrada do aluno no diálogo com os gêneros discursivos e que possam promover discussões críticas, aprimorando a sua capacidade de leitura.

De modo geral, através da experiência de prática docente no CF do IFA, percebemos como o papel do professor é fundamental na apropriação dos conceitos 
teórico-metodológicos para a elaboração dos materiais didáticos e na mediação do processo de interlocução dos alunos com os gêneros discursivos. Sobre esse último aspecto, vale destacar também que a integração das Tecnologias da Informação e da Comunicação em Educação (TICE), nos processos de ensino-aprendizado, tornou possível um diálogo mais efetivo entre os alunos e os discursos em língua estrangeira. Isso porque, justamente no ano de 2012, foi inaugurado o Laboratório de Línguas do IFA, uma sala de aula adaptada com móveis e 12 computadores adquiridos pela PRAE, da qual pudemos usufruir ao longo do período de atuação no CF.

Para concluir, ainda que não tenha sido possível dar uma visão mais precisa, na íntegra, do material empírico usado como exemplo nesse estudo, a nossa intenção principal foi a de discutir aspectos teórico-metodológicos importantes relacionados ao modo de organização dos conteúdos no esqueleto de uma UT do curso e à exploração pedagógica dos gêneros discursivos. Temos convicção de que a análise realizada e a experiência compartilhada podem auxiliar na construção de parâmetros norteadores para a estruturação de cursos que sigam perspectivas pedagógicas semelhantes as do IFA.

\section{REFERÊNCIAS}

ANTUNES, I. Muito além da gramática: por um ensino de línguas sem pedras no caminho. São Paulo: Parábola Editorial, 2007.

BAKHTIN, M. M. Os gêneros do discurso. In: BAKHTIN, M. M. Estética da criação verbal. Tradução de G. E. M. Pereira. São Paulo: Martins Fontes, 1992. p. 277-326.

BAKHTIN, M. M. O discurso no romance. In: BAKHTIN, M. M. Questões de Literatura e de Estética. Teoria do Romance. São Paulo: UNESP/Hucitec, 1998.

CAPELLE, G.; GIDON, N. Reflets 1. Méthode de français. v. 1. Paris: Hachette Livre Français langue étrangère, 1999.

CUQ, J.; GRUCA, I. Cours de didactique du français langue étrangère et seconde. Grenoble: Presses Universitaires de Grenoble, 2005.

FOUCAMBERT, J. A leitura em questão. Porto Alegre: Artes Médicas, 1994.

FOUCAMBERT, J. Modos de ser leitor. Curitiba: Editora UFPR, 2008.

NERY, R. M. Questões Sobre Questões de Leitura. Campinas: Editora Alínea, 2003. 
PICANÇO, D. C. L. História, memória e ensino de espanhol (1942-1990): as interfaces do ensino da língua espanhola como disciplina escolar partir da memória de professores, métodos de ensino e livros didáticos no contexto das reformas educacionais. 1. ed. Curitiba: Editora da UFPR, 2003.

PICANÇO, D. C. L. Autoria, produção de texto e editoração de livros artesanais como práticas culturais. In: CONGRESSO INTERNACIONAL DE ESTUDOS EM

LINGUAGEM, 2. Anais eletrônicos [...]. Campinas, Galoá, 2017. Disponível em: https://proceedings.science/ciel-2017/papers/autoria--producao-de-texto-e-editoracaode-livros-artesanais-como-praticas-culturais-. Acesso em: 4 fev. 2021.

PUREN, C. Histoire des méthodologies de l'enseignement des langues. Paris: Cle International, 1988. Disponível em: http://www.christianpuren.com/mes-travaux/1988a/. Acesso em: 14 jul. 2020.

ROJO, R. A teoria dos gêneros discursivos do Círculo de Bakhtin e os multiletramentos. In: ROJO, R. H. R. (org.). Escol@ conectada: os multiletramentos e as TICs. São Paulo: Parábola Editorial, 2013.

VAILATTI, T. F. La bande dessinée, pour quoi faire? Uma análise das histórias em quadrinhos nos livros didáticos de francês língua estrangeira. 2016. Dissertação (Mestrado em Educação). Setor de Ciências Humanas e Educação, Universidade Federal do Paraná, Curitiba, 2016.

VOLÓCHINOV, V. (Círculo de Bakhtin). Marxismo e filosofia da linguagem. Problemas fundamentais do método sociológico na ciência da linguagem. Tradução, notas e glossário de Sheila Grillo; Ekaterina V. Américo. Ensaio introdutório Sheila Grillo. São Paulo: Editora 34, 2017.

TILIO, R. Repensando a abordagem comunicativa: multiltramentos em uma abordagem consciente e conscientizadora. In: ROCHA, C. H.; MACIEL, R. (org.). Língua estrangeira e formação cidadã: por entre discursos e práticas. 1. ed. Campinas: Pontes, 2013, v. 1, p. 51-67. 